\title{
Integrated primary care and social services for older adults with multimorbidity in England: a scoping review
}

\author{
Hajira Dambha-Miller ${ }^{*}$, Glenn Simpson ${ }^{1}$, Lucy Hobson ${ }^{1}$, Paul Roderick², Paul Little ${ }^{1}$, Hazel Everitt ${ }^{1}$ and \\ Miriam Santer ${ }^{1}$
}

\begin{abstract}
Background: As the prevalence of older adults with multimorbidity increases, greater integration of services is necessary to manage the physical and psycho-social needs of this cohort. This study describes and summarises current evidence, clinical provision and progress towards integrated primary care and social services for older adults with multimorbidity in England.
\end{abstract}

Methods: A scoping review was conducted involving systematic searches of a range of electronic academic and policy databases. Articles were screened and extracted in duplicate by two independent reviewers. Data were extracted onto a charting sheet and thematic synthesis was used to summarise findings. Articles were included if published in English and related to primary care, social care and multimorbidity in older adults in England. Conceptually, the review was framed using the Rainbow Model of Integrated Care.

Results: The search yielded 7656 articles of which 84 were included. Three themes were identified: (1) a focus on individual level services rather than multi-level or multi-sector integration, with an increasing emphasis on the need to consider broader determinants of population health as critical to integrated care for older adults with multimorbidity; (2) the need for policymakers to allow time for integration to embed, to enable new structures and relationships to develop and mature; and (3) the inherent tension between top-down and bottom-up driven approaches to integrated care requires a whole-systems structure, while allowing for local flexibilities.

Conclusions: There is limited evidence of multi-level and multi-sector integration of services for older adults with multimorbidity in England. The literature increasingly acknowledges wider determinants of population health that are likely to require integration beyond primary care and social services. Improving clinical care in one or two sectors may not be as effective as simultaneously improving the organisation or design across services as one single system of provision. This may take time to establish and will require local input.

Keywords: Integrated care, Older adults, Multimorbidity, England

*Correspondence: H.Dambha-Miller@soton.ac.uk

${ }^{1}$ Primary Care Research Centre, University of Southampton, Aldermoor

Health Centre, Aldermoor Close, Southampton SO16 5ST, UK

Full list of author information is available at the end of the article

\section{Introduction}

Closer health and social care integration has been a key policy goal of successive UK governments for 40 years but the advancement of this agenda has not been achieved at the pace required to meet the demands of an increasingly ageing population with higher levels of multimorbidity $[1,2]$. Recent prediction forecasting of care dependency 
profiles suggests that $80 \%$ of the ageing population, that is people aged 65 years or older according to the UK National Health Service, will require medium or high dependency care due to multimorbidity [3]. In this context, it is essential that primary care is capable of working closely with social services and wider community care providers to harness collective capacity, which can address the range of behavioural, social, and physical health care needs of the population. This requires more careful consideration of the organisation, structures, systems and funding across providers to identify specific opportunities for successful integration. The scoping review adopted Leutz's definition of integration 'as the search to connect the healthcare system (acute, primary medical and skilled) with other human service systems (e.g. long-term care, education and vocational and housing services) to improve outcomes (clinical, satisfaction and efficiency).' [4].

Given the substantial funding provided for integration pilots including a variety of testbeds, and the extensive research and evaluation in practice that has already been conducted [5], it is valuable to learn from these to understand current progress and anticipate future challenges to successful implementation. Whilst previous reviews have been conducted, these have mainly been limited to searches of the published literature, which may not adequately capture efforts in private or voluntary sector care organisations, where most social care is provided [6-9]. Moreover, few earlier studies have specifically examined the literature related to England in order to consider the contextual factors of this setting. There is also a relative paucity of evidence that considers integration in relation to primary care, where most care of older adults with multimorbidity occurs $[7,10]$. To address these gaps in the evidence base, a scoping review was conducted to describe and summarise current evidence, clinical provision and progress towards integrated primary care and social services for older adults with multimorbidity in England.

\section{Methods}

\section{Review approach and conceptual framework}

The study followed the Preferred Reporting Items for Systematic Reviews and Meta-Analyses (PRISMA) guidelines for scoping reviews [11]. The scoping review allowed rapid mapping out of key existing work and current progress in this field. Conceptually, the review was framed using the Rainbow Model of Integrated Care, a framework that permits better definition and understanding of integrated care from a primary care perspective [12]. This multi-level conceptual framework describes dimensions that play inter-connected roles on the macro- (system integration), meso- (organisational and professional integration) and micro-level (clinical, service and personal integration), alongside dimensions (functional and normative integration) that enable the integration between different levels within a health system [13]. The model promotes the provision of continuous, comprehensive and coordinated care to the individual and population [12].

\section{Search strategy}

A systematic electronic search was conducted in Medline, EMBASE, The Cochrane Library, Web of Science, the Cumulative Index to Nursing and Allied Health Literature, and Science and Social Science Citation Indices from database inception until the 16th June 2020. For searches of electronic databases, text and MeSH terms were limited to primary care, social services and older adults. Detailed search terms are available in supplementary file. Unpublished literature was searched for in Opengrey and through the websites of Clinical Commissioning Groups, GP federations, the Department of Health and Social Care, third sector bodies and private organisations who deliver social care. Hand searching of the bibliographies of included works and relevant systematic reviews for any additional relevant data was conducted. The views of topic experts and service users were sought to source further data. All articles identified were imported into Rayyan software for screening, which was conducted in blinding mode.

\section{Inclusion/exclusion criteria}

Articles were eligible for inclusion if published in the English language and their content was primarily related to the key inclusion/exclusion criteria of primary care, social care and multimorbidity in older adults, specifically in England. Due to the broad aim of this scoping review, researchers adopted flexibility in study designs including newsletters, discussion papers, government reports, company reports, blogs, working papers, policy recommendations, webinars and dissertations. Quality assessment is not a priority for scoping reviews, therefore articles were not excluded on this basis.

\section{Study selection and data extraction}

Titles and abstracts were screened with each article assessed for relevance according to the inclusion criteria. Full-text articles were retrieved. Both screening and data extraction were carried out independently by two reviewers. A data charting form was used, which was specifically designed according to the study conceptual framework described above. The level of integration within each included article was examined in line with the Rainbow Model of Integrated Care conceptual framework (i.e. macro, meso or micro-level and vertical/ 
horizontal integration), article characteristics and key findings.

A list of data extracted on the charting form is summarised in Table 1 below. Any disagreement between reviewers about data was resolved through discussion until a consensus was reached.

\section{Summarising and analysis}

Researchers used counts to summarise article characteristics, and the charting technique to iteratively synthesise and interpret findings by sifting and sorting material [14, 15]. Repeated reference to the study conceptual framework was made during this process. Using thematic synthesis, key excerpts of extracted text were first coded by three members of the team (HDM, GS and SH). Deductive analysis was used in deriving a conceptual framework from the research aims and theory, while also seeking to inductively identify codes and themes from the synthesis of included articles. Initial codes were refined into themes. Members of the team experienced in systematic reviewing who had not previously been engaged in the coding process, were involved in the final stages of the analysis. This provided an additional perspective on the analytical process to strengthen both the quality and validity of the findings.

\section{Results}

In total 7656 articles were identified including 6426 from electronic databases, 1118 via Opengrey and 112 from websites and experts. Following title and abstract screening, 809 articles underwent full-text screening, which resulted in a final 84 articles being included in the review. A flowchart of the screening process, including the reasons for exclusion, is shown in Supplementary material [16].

Table 1 Summary of data charting form

\section{Characteristics of included studies}

The 84 included articles represented multiple locations across England, including regions in the south-west, north-east, north-west and Greater London. These were from a range of sectors; primary care, secondary care, social care, voluntary sectors, local government, local authority and public health. The most frequent study designs or types were qualitative $(n=18)$, followed by mixed-methods $(n=12)$, analysis/commentaries $(n=12)$, systematic/scoping/evidence reviews $(n=10)$, randomised controlled trials $(n=9)$, policy documents $(n=8)$, quantitative studies $(n=7)$, thesis $(n=4)$, editorials $(n=2)$ and books/book reviews $(n=2)$. Included articles were published between 1996 and 2020. The characteristics of included articles have been summarised in Table 2.

\section{Level of integration}

The number of studies that considered integration were counted at each level as set out in the conceptual framework (i.e. macro, meso or micro-level). There were $7 \%$ of studies that considered integration at the macro-level, $5 \%$ at meso-level and 30\% at micro-level. Thirty-five per cent of the articles considered integration at all three levels. However, the combined number of studies focused on either one or both of micro and meso levels was $52 \%$.

\section{Summary of themes amongst included studies}

Three themes were identified from the analysis, which summarised current research and progress on integrated primary care and social services for older adults with multimorbidity in England: (1) a diverse focus on multi-level vs. multi-sector integration; (2) time needed for integration to embed; and (3) seeking structural integration while applying local flexibility. Each of these is described in turn below.

- Title

- Author

- Year

- Study design (RCT, Scoping Review or Case Study etc)

- Geographical Location (Manchester, Norfolk or London, etc)

- Setting (Social care, primary care or care home etc)

- Sample type (GP, patient, social worker or relative, etc)

- Source of data (Primary research, secondary analysis or commentary, etc)

- Primary aim of study, research or document (As set out in study abstract)

- Method (Questionnaire, semi-structured interviews or scoping review, etc)

- Key findings/themes (As set out in study abstract)

- Examples of integrated care provided (Any examples of integrated care practice, initiatives, structures, models, etc., e.g. Case Management Model, Chronic Care Model; Social Prescribing)

- Clinical or practice integration (micro-level), e.g. the extent to which staff, management and patient records etc., are integrated

- Organisational integration (meso-level), e.g. the extent to which integration of services has been achieved across different organisations

- System integration (macro-level), e.g. the degree of alignment of rules and integration of policies within a health and social system. 


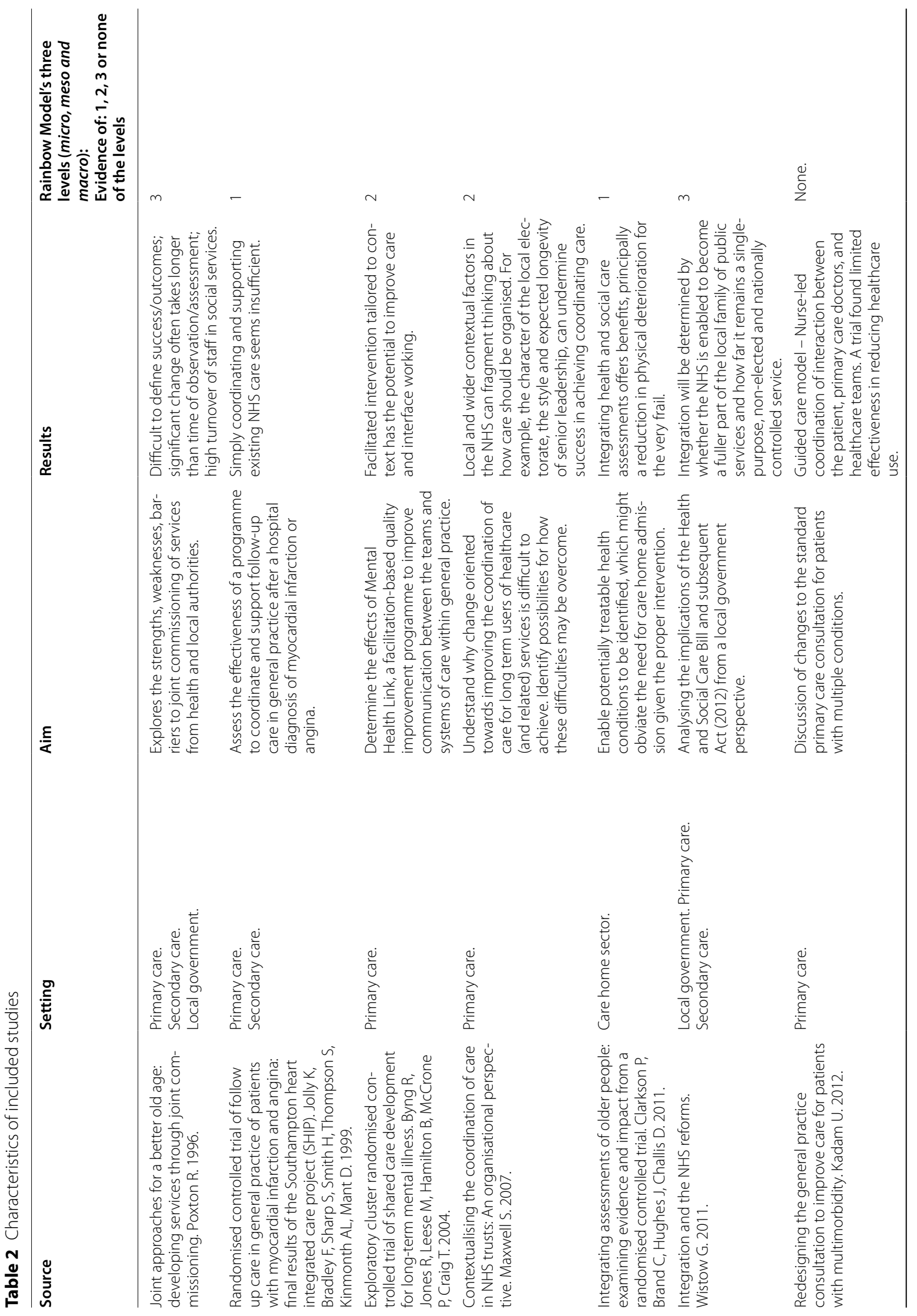




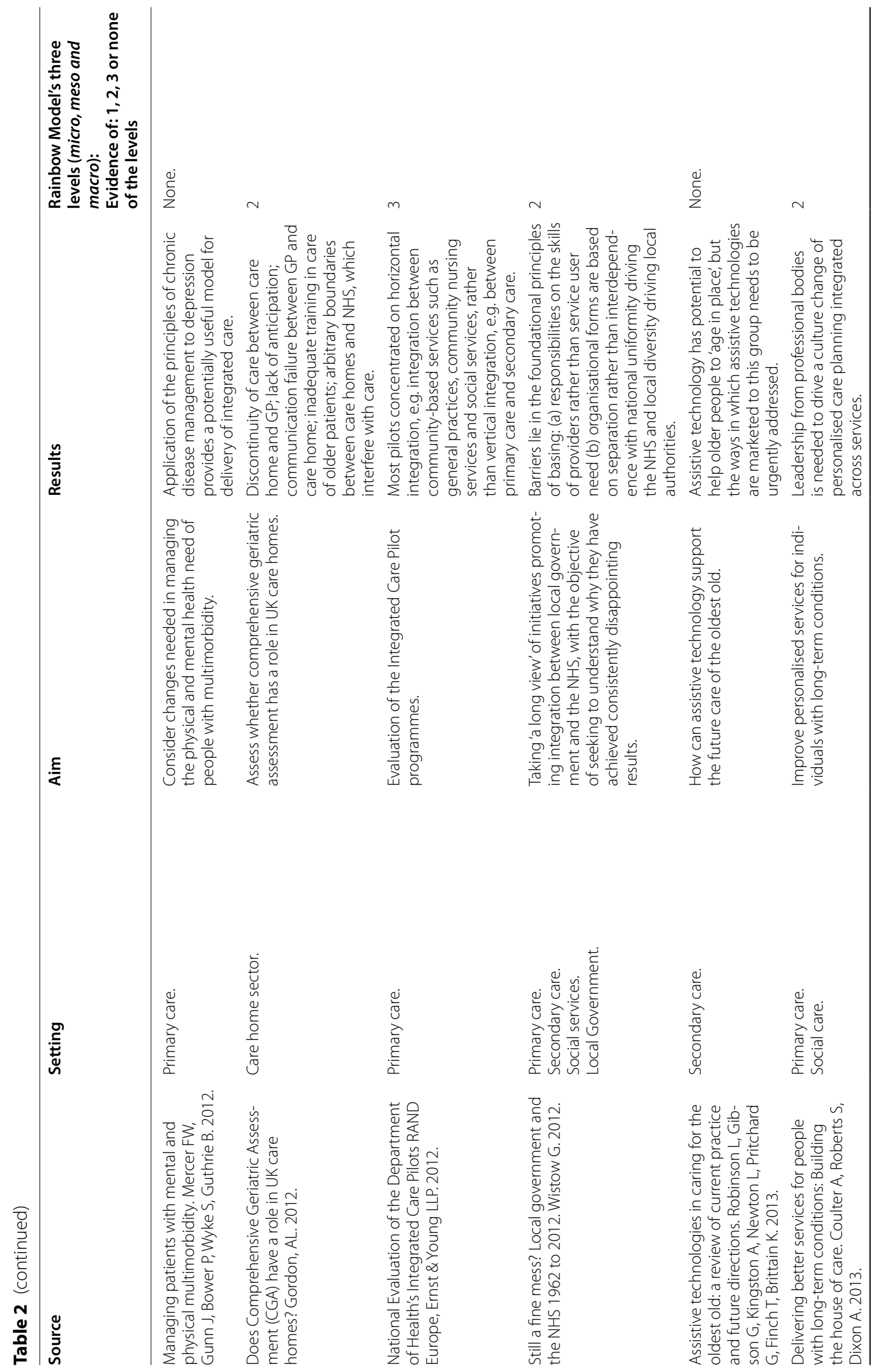




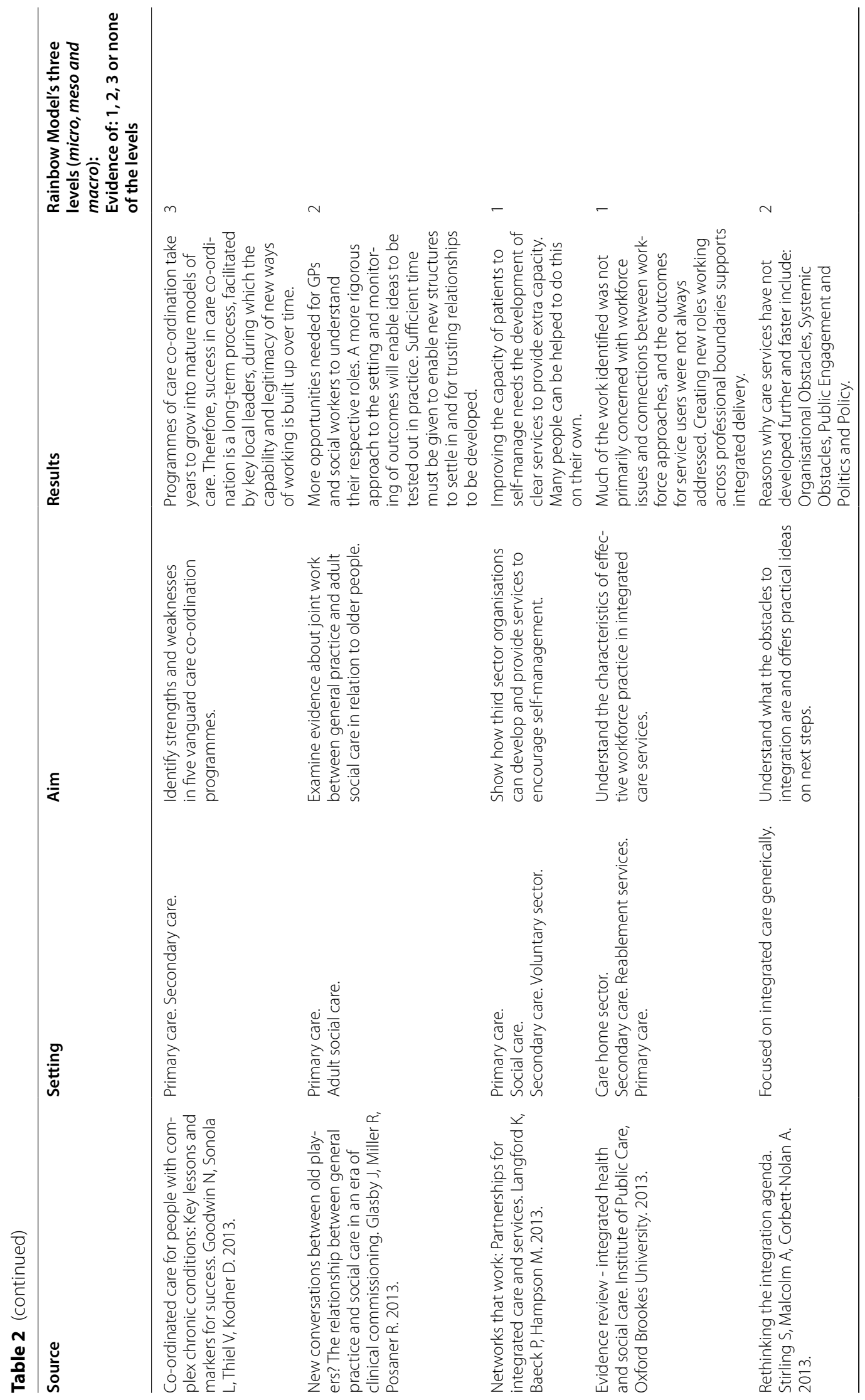




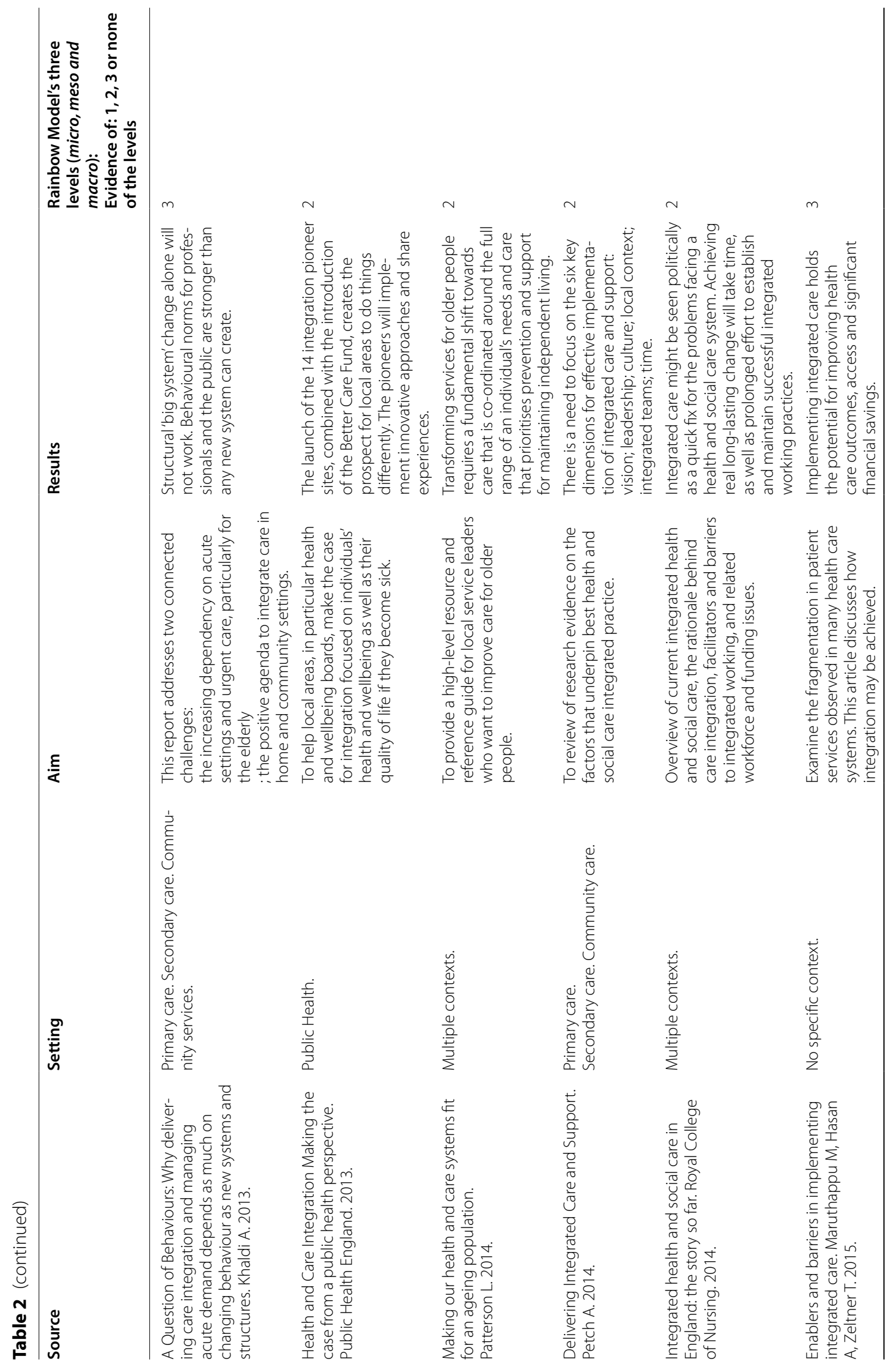




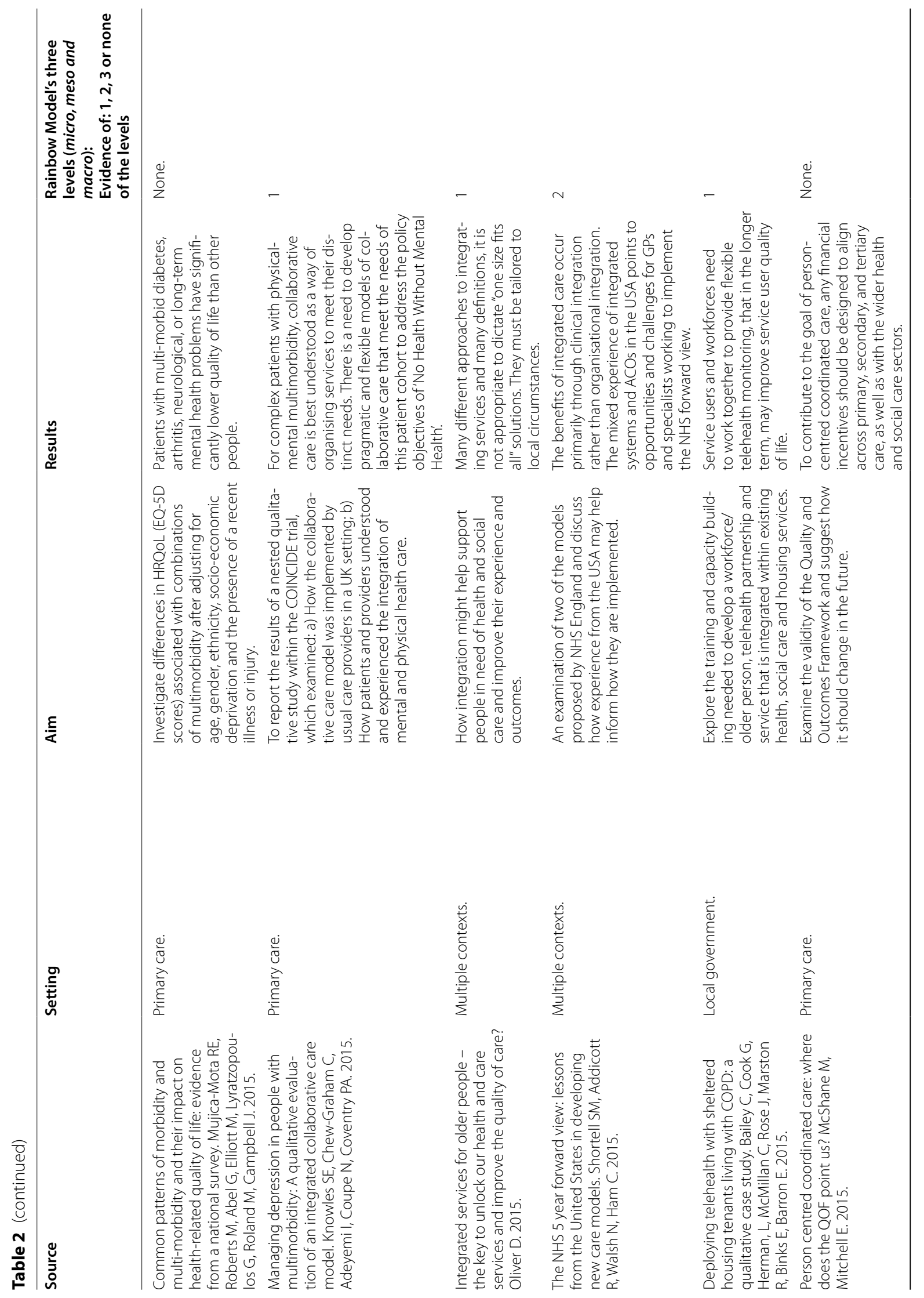




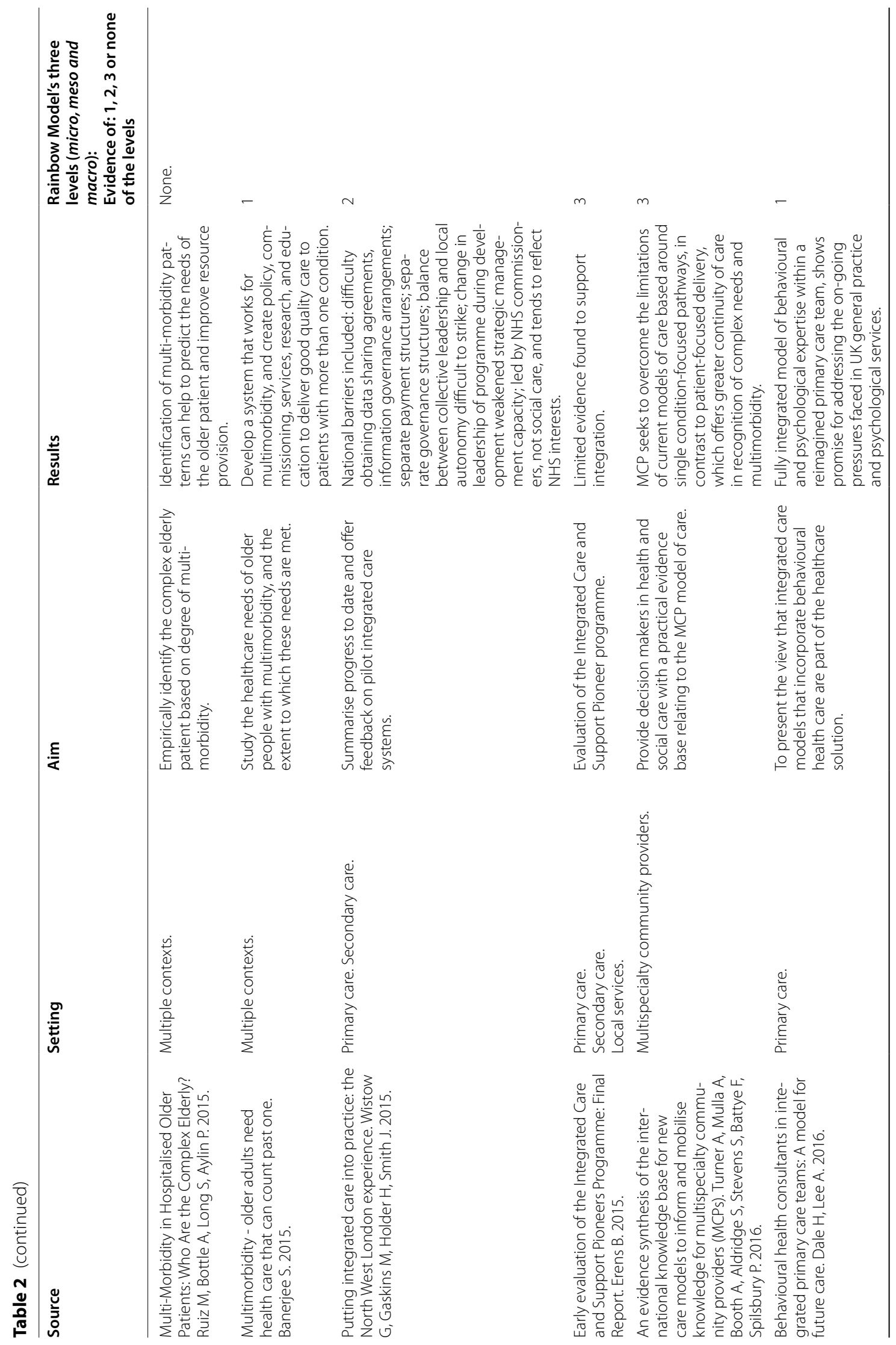




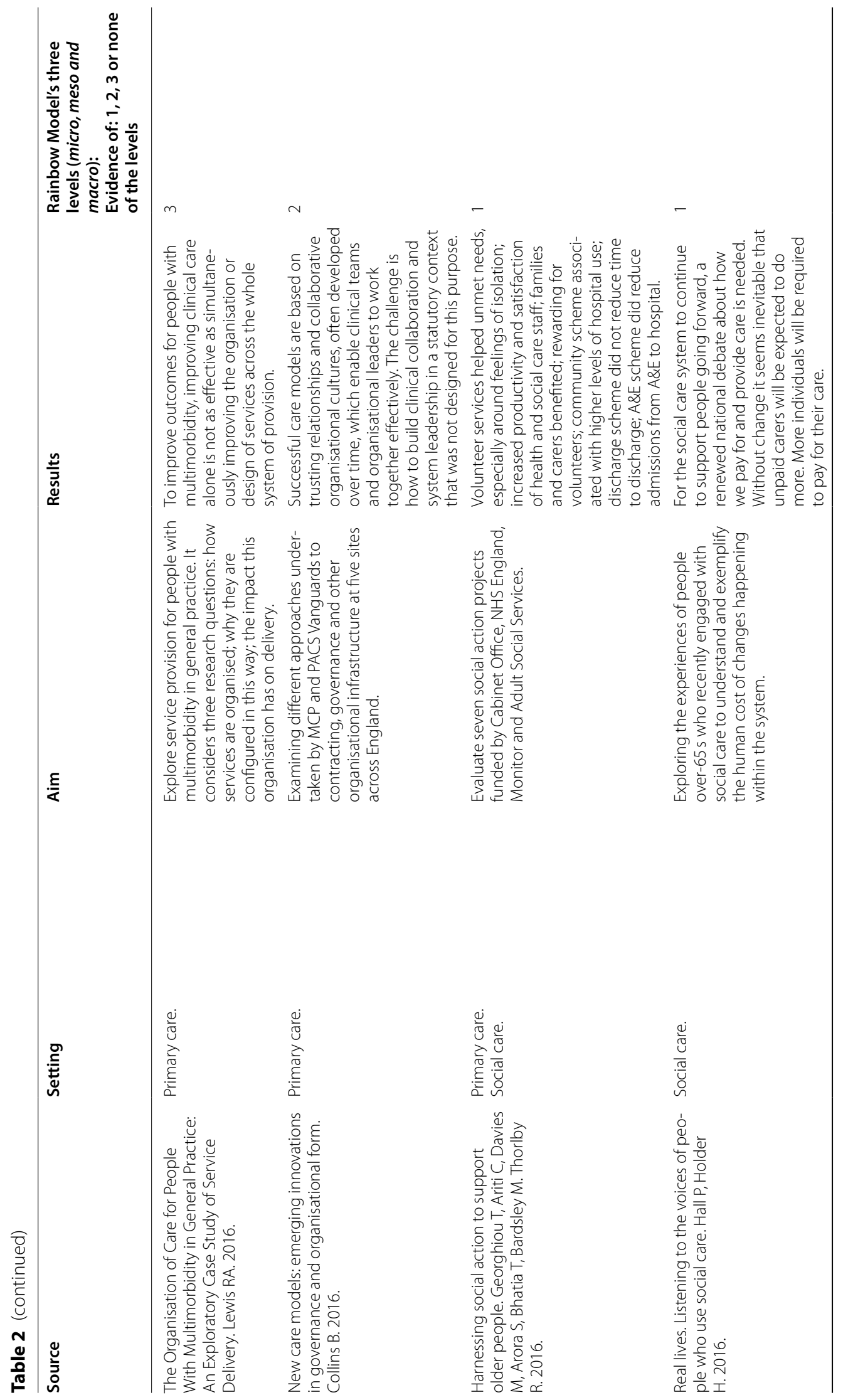




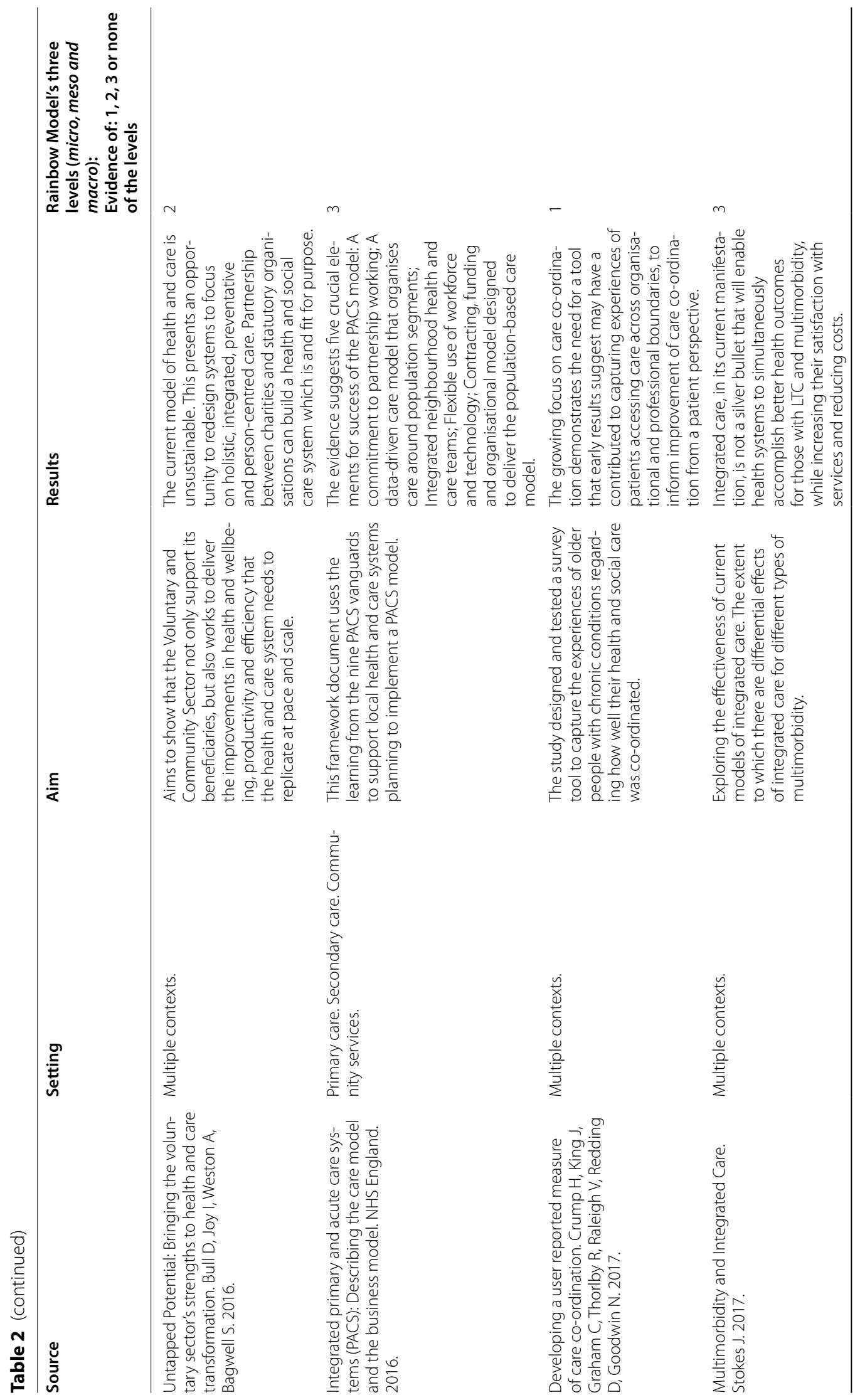




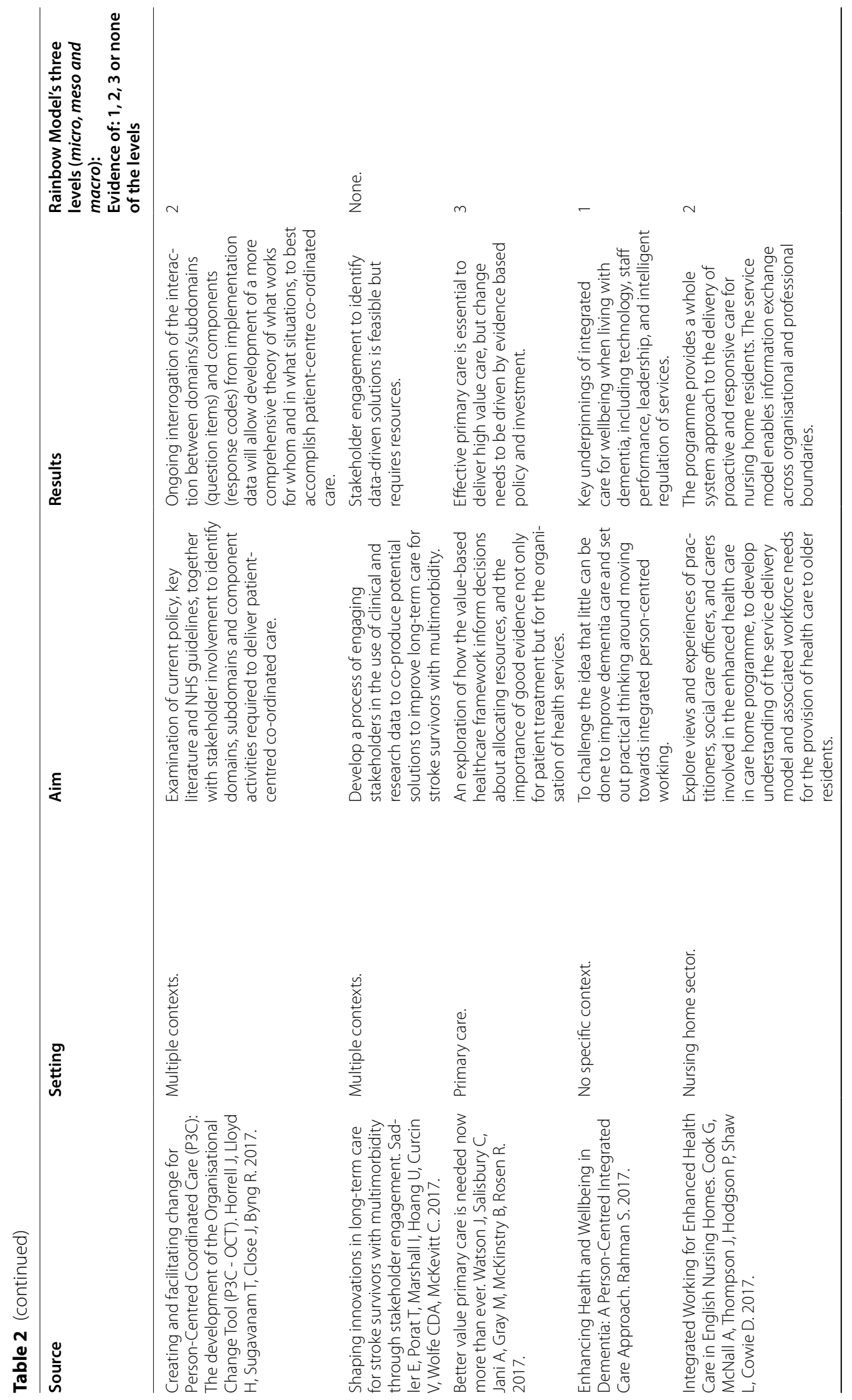




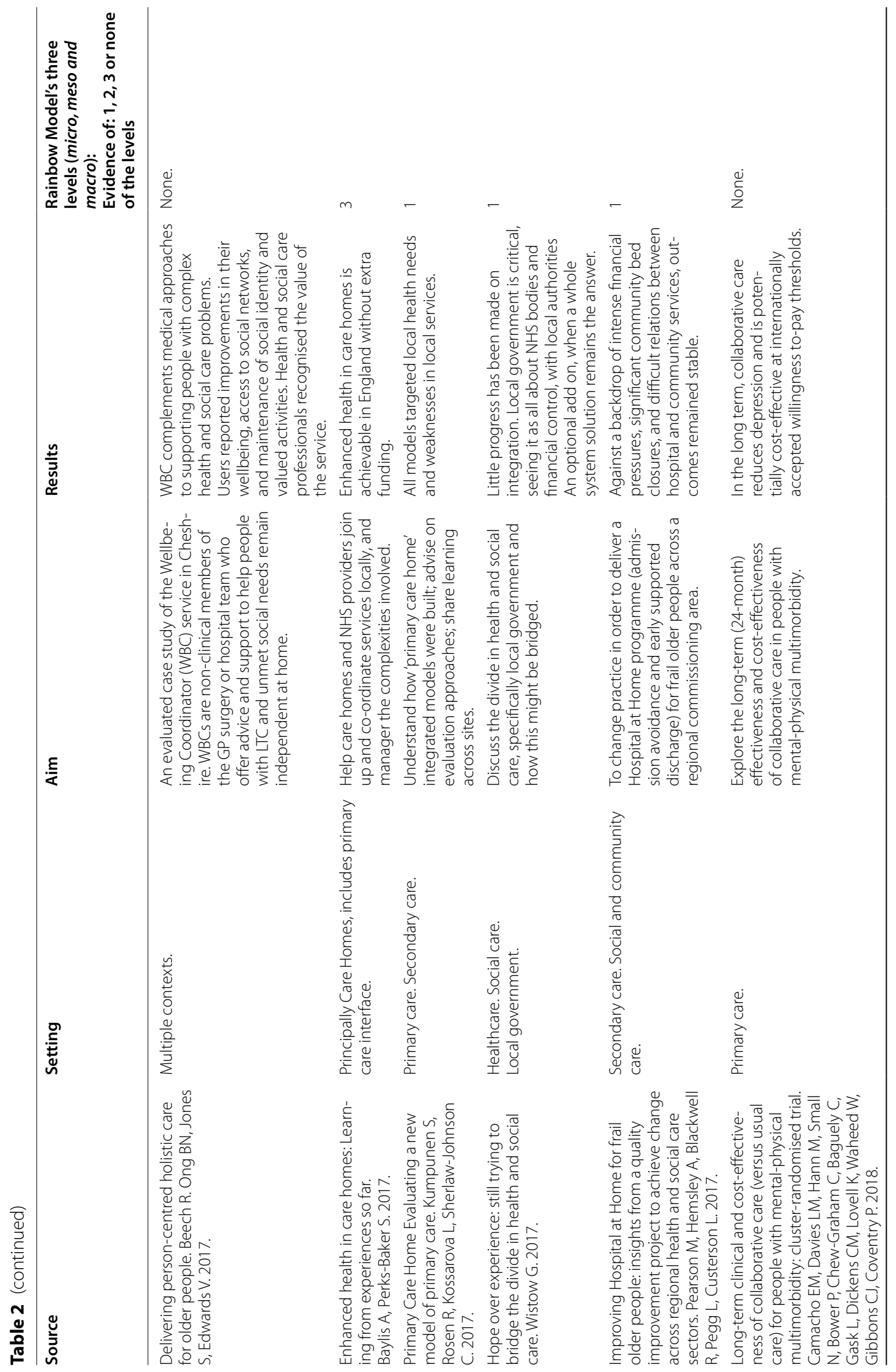




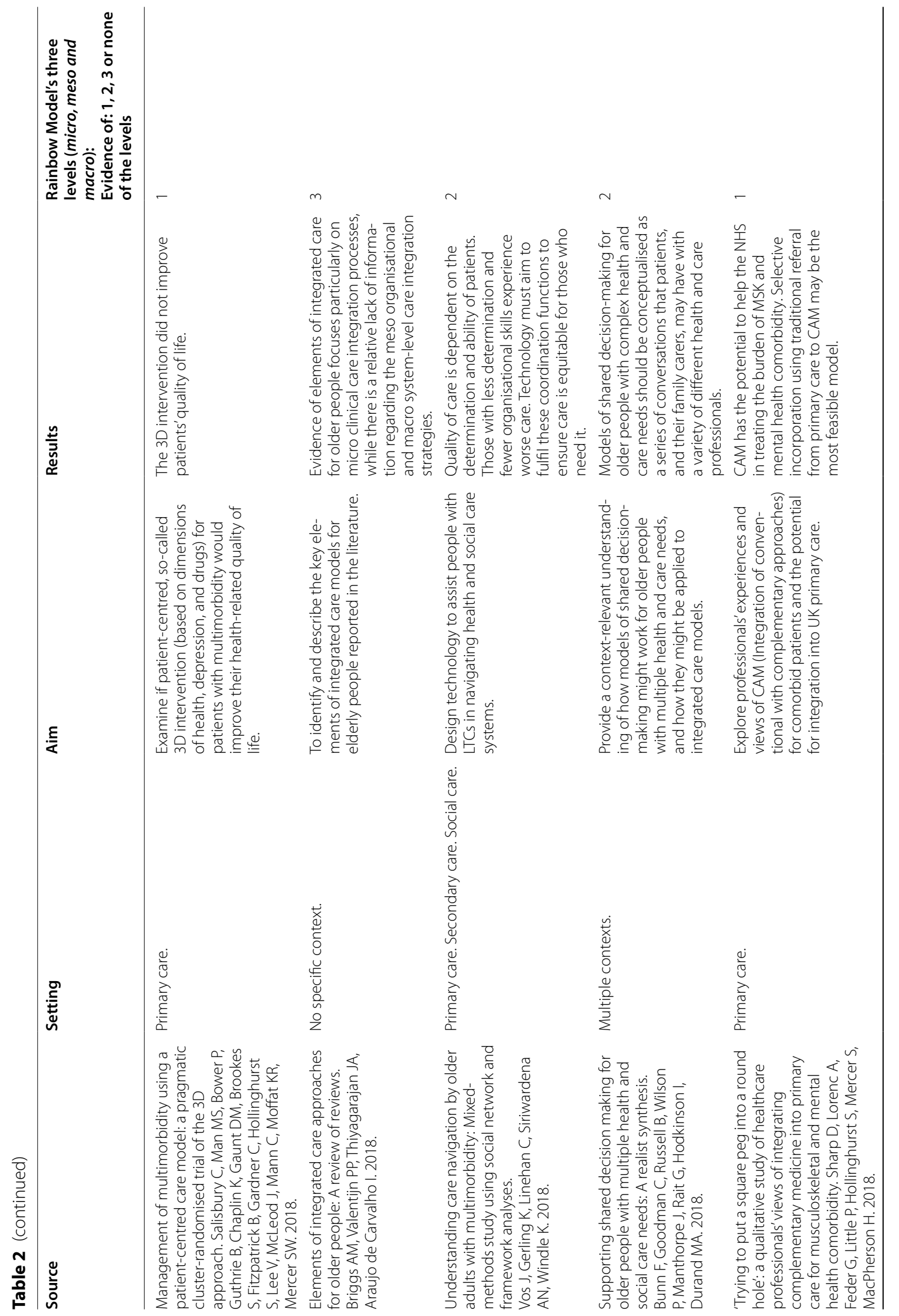




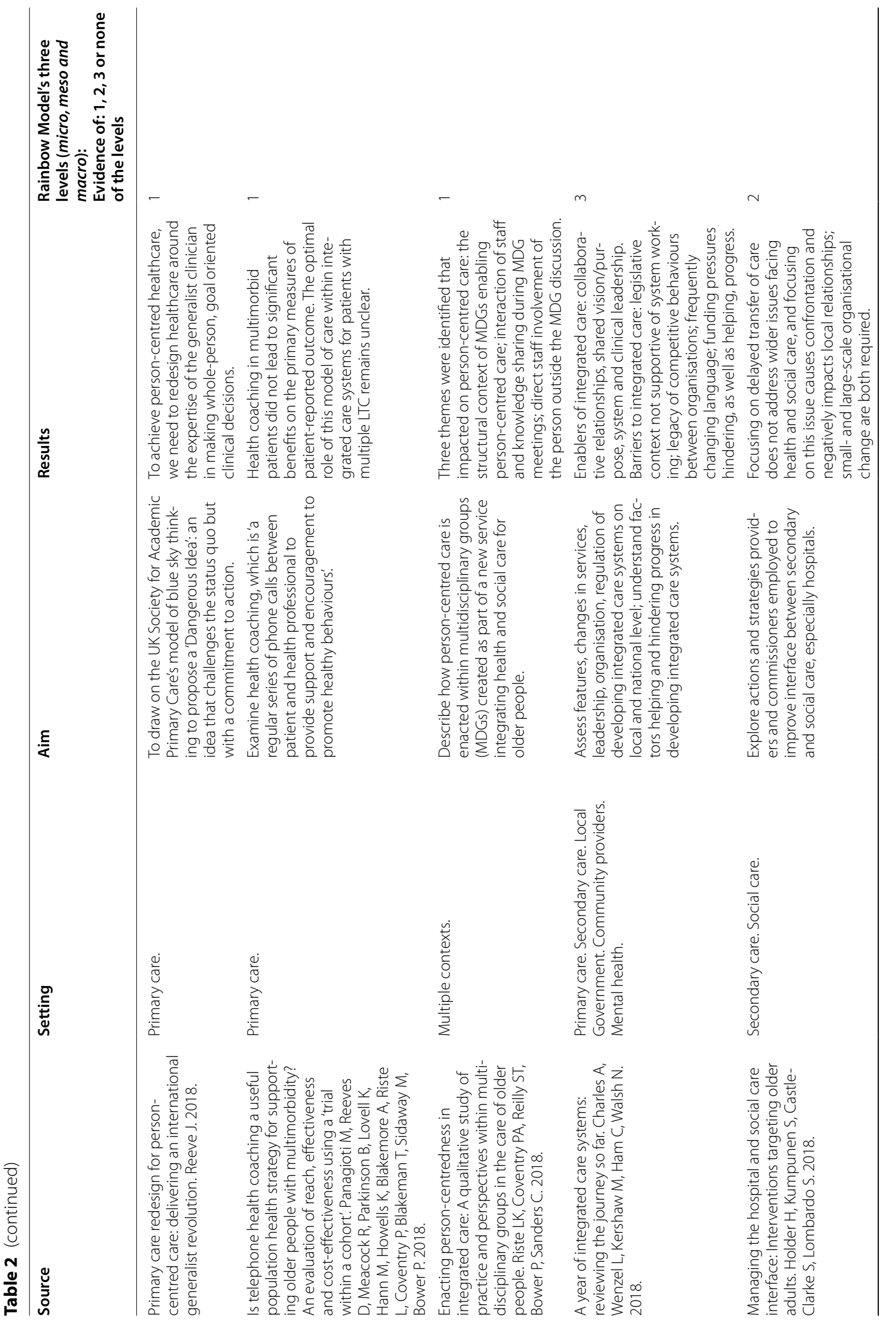




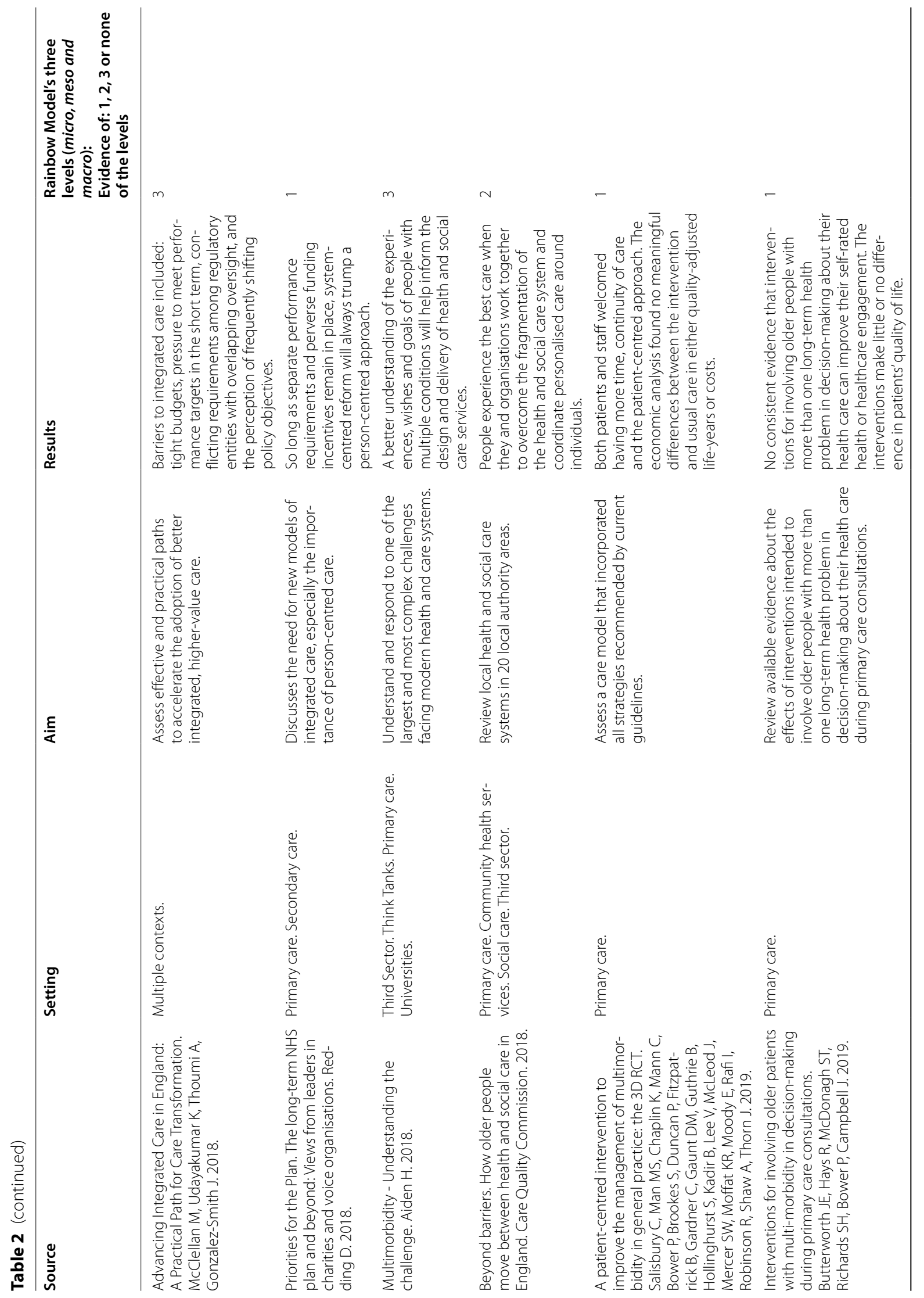




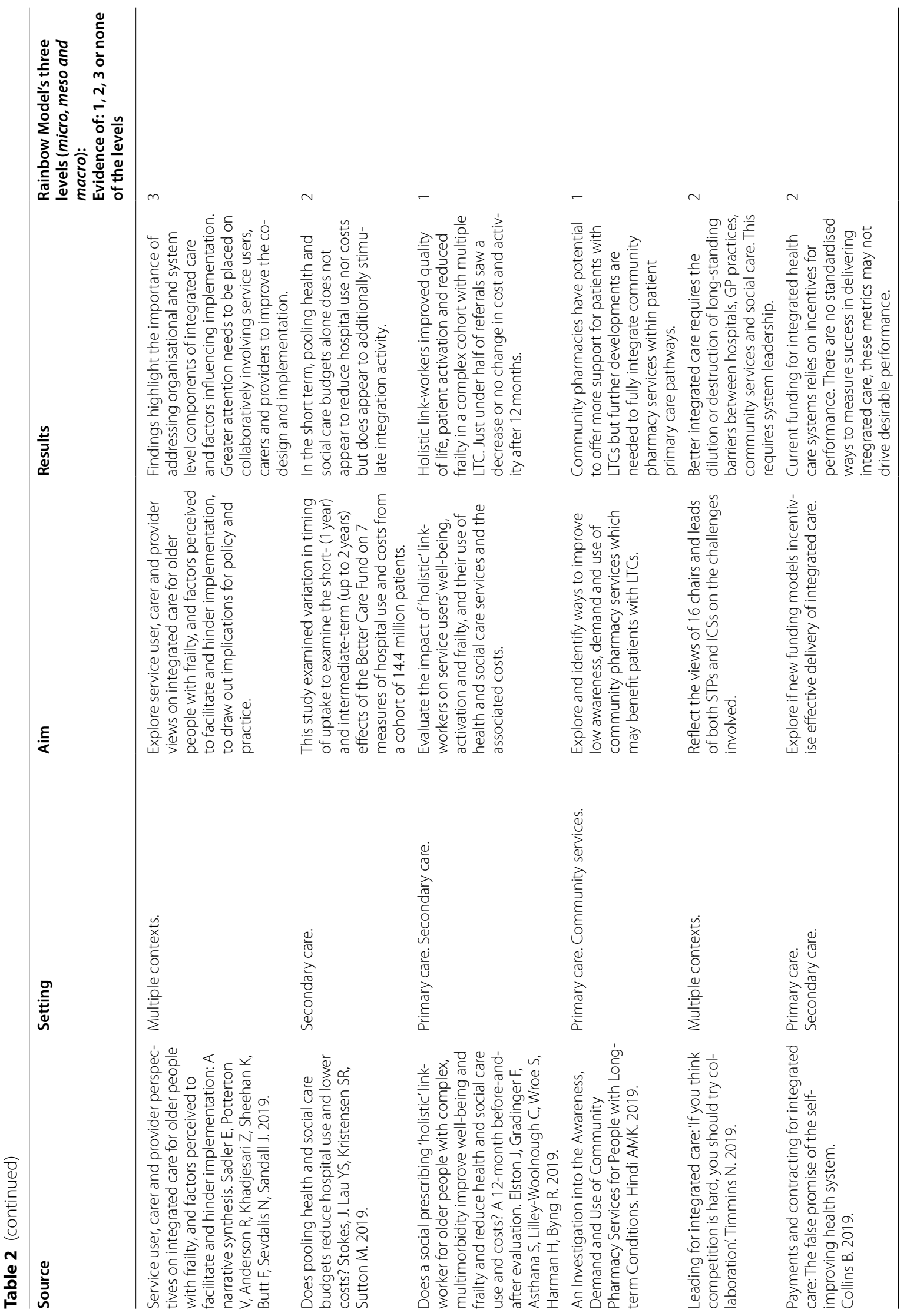




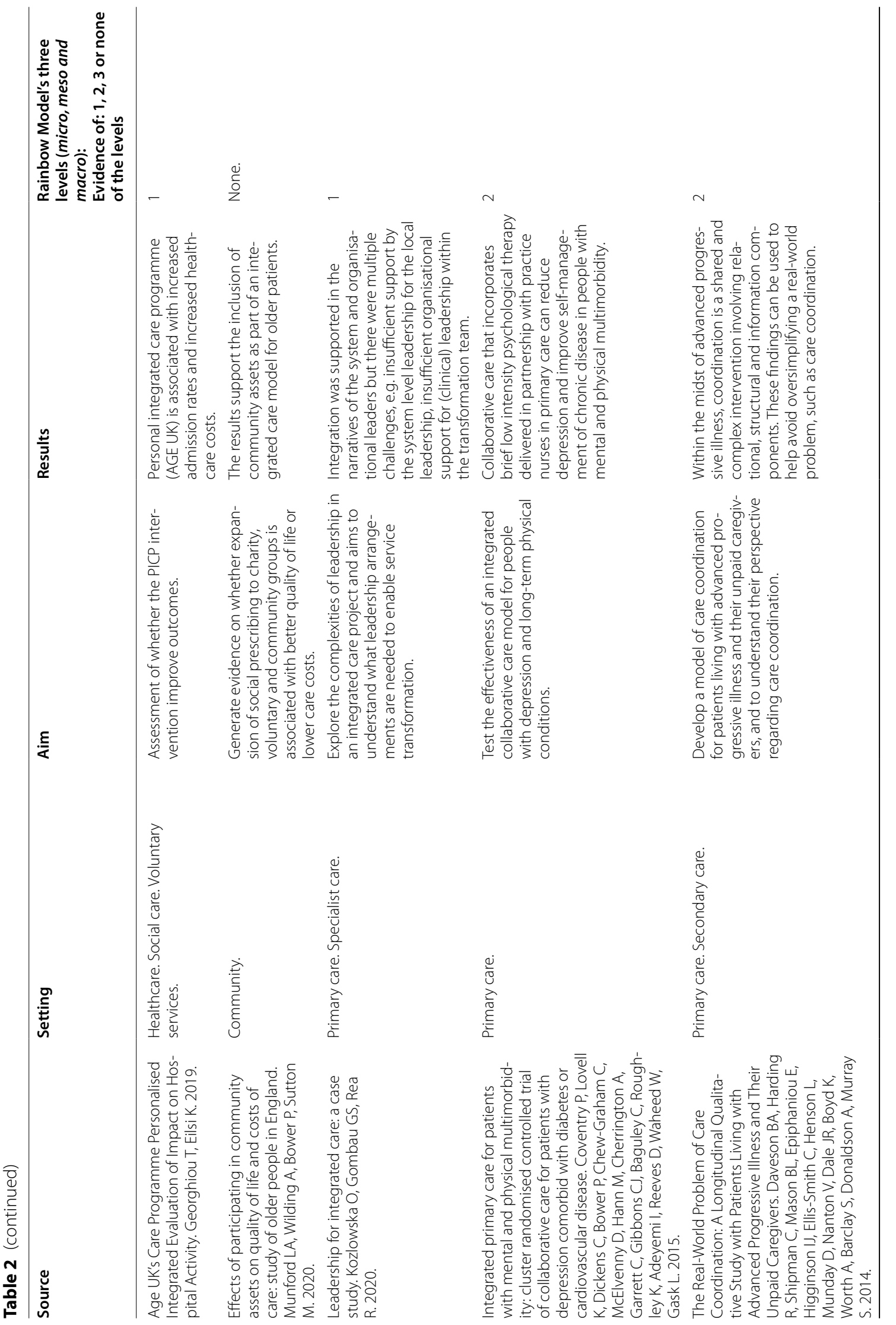




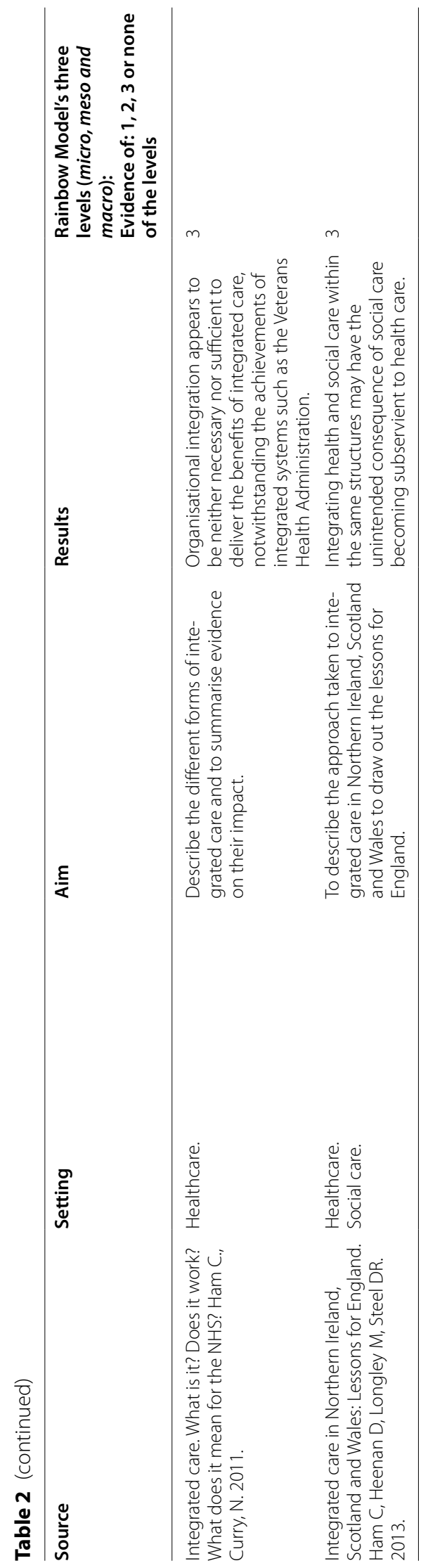




\section{Multi-level and multi-sector integration}

Several articles described previous research and clinical provision in primary care or social services for older adults with multimorbidity in England [17-20]. These were often concerned with particular sectors (e.g. primary care) or scales of integration (e.g. clinical level), rather than whole-systems reform [21-27]. Studies focused on improving specific dimensions of integration such as leadership $[17,28]$, care models [22, 29-32] or considered integrated working from the perspective of one or two levels of integration [33-36], most frequently the micro-scale or the micro/meso-scales together. Little evidence was found of functional or normative forms of, or approaches to, integration as described in the Rainbow Model of Integrated Care conceptual framework [12]. Studies from 1996 onwards repeatedly stressed the need for more multi-level, systemic and comprehensive integration [37, 38], although limited evidence was found of significant progress in achieving this ambition over the last two decades. A prevalent theme was the urgent requirement to mitigate or remove long-standing barriers to integration, such as incompatible record sharing systems and inadequate information sharing processes between sectors [39-43]; 'siloed' thinking in service provider organisations [44-46]; poor communication among health and social care professionals, both internally within their organisations and across sectoral boundaries [47-49]. There was an increasing emphasis on the need to tackle wider determinants of population health with suggestions that to achieve this, it is necessary to go beyond primary care and social services to include hospitals, GP community services, voluntary sectors and local government partners [10, 32, 48, 50,51]. There was a growing recognition in more recent literature that improving clinical care in one or two sectors may not be as effective as simultaneously improving organisation or design across services, as one system of provision [43]. Solutions that were proposed emphasised the need for system-wide leadership across all scales, alongside a shared vision of integrated working across sectors [52-55]. There was evidence highlighting the importance of the quality and style of organisational leadership, both in terms of delivering change and maintaining an integrated approach to service delivery $[9,28,56]$. Few examples were found of where this approach had led to individual and local successes, and widespread evaluation and evidence of application was very limited $[31,34,47,57]$.

\section{Time for integration to embed}

A number of studies highlighted that integration requires time to allow new structures and relationships to develop and bed-in. Integrated care programmes take years to establish and need sufficient time to allow new care models to fully mature $[19,58-60]$. Effective and enduring integration is 'the result of a long-term process, facilitated by key local leaders, during which the capability and legitimacy of new ways of working is built up over time' [50]. The King's Fund report of the Vanguards concluded that the most successful models of integrated care are built on 'trusting relationships and collaborative organisational cultures', which 'often developed over time,' enabling 'clinical teams as well as key organisational leaders to work together effectively' [29]. This highlights the importance of time in supporting and sustaining long term individual, inter-professional and co-operative organisational relationships and cultures, which are a key component of normative integration [12], understood as "the development and maintenance of a common frame of reference (i.e., shared mission, vision, values and culture) between organizations, professional groups and individuals" [61].

Some studies suggest that the answer to the challenges of integration may lie in persistence and perseverance over several years to enable integrated care programmes to achieve their 'objectives and become self-sustaining' $[53,62,63]$. This appeared to be influenced by the sustained commitment of key partners and the 'longevity of the senior leadership' [57]. The challenge in the next phase of integrated care reform is 'building clinical collaboration and system leadership in a statutory context' that is 'not designed for this purpose', [29] alongside policymakers providing the necessary time for integrated care programmes to 'evolve and mature', [64] rather than moving onto the next new policy initiative.

\section{Structure with flexibility}

The scoping review identified inherent tensions between top-down and bottom-up driven approaches to integrated care, in particular, having in place a single comprehensive 'whole-systems' structure combined with local flexibilities. Studies suggested that integration should be implemented within a clear framework and a set of higher-level principles that allows for both macrolevel systems-wide strategic management and oversight, combined with local autonomy and flexibility, described as 'structured flexibility' $[19,65-68]$. The benefit of holistic systems-wide approaches is that they 'tend to be more strategic with clearer paths for scaling up, compared to 'bottom-up' approaches driven by highly motivated individuals at the micro-level' [56]. Nevertheless, a whole-systems strategy requires a twin-track approach [55], with 'leadership from the bottom up' driven by staff who are 'empowered to integrate services where they see the need' [53]. Mechanisms for horizontal integration (structures, strategies and practices that connect care across the same level in the system) [12], were also 
seen as essential 'at each organisational level (for example whole systems, community and individual levels). Vertical mechanisms (structures, strategies and practices which link together services up and down the different scales of the system) are also necessary 'to integrate the various levels' [37, 42]. Successful examples of integrated care in the NHS indicate that when this is 'pursued at all levels', it could 'overcome the risks of fragmentation, and of 'service users falling between the cracks' of care [69]. Critically however, the studies included in the review suggested that any programme of integrated care must be based on an understanding that 'as barriers to integration are systemic in organisations designed for separation rather than integration and the historic paradigms of building bridges and tearing down walls is inherently flawed, and of limited effectiveness: a better metaphor is one of weaving integration into the fabric of organisational life' [37].

\section{Discussion}

This scoping review aimed to summarise current evidence, clinical provision and progress on integrated primary care and social services for older adults experiencing multimorbidity in England. The findings highlight a paucity of research evidence and clinical practice pursuing multi-level or multi-sector integration across services. Furthermore, existing literature in this field are often limited to individual sectors [21-27]. The value of considering primary care and social services alongside local government, third sector and secondary care organisations in tackling the broader determinants of population health was frequently emphasised [10, 32, $48,50,51]$. In addition, several studies highlighted that integration requires time $[19,58-60]$ to allow new structures and relationships to evolve and mature. The recent development of the Primary Care Network (PCN) Maturity Matrix, as a methodology and systems development approach, has potential to address this issue. PCN sets out a developmental pathway or framework to guide systems leaders, which focuses attention on the importance of allowing integrated care programmes sufficient time to bed-in and reach a state of maturity [70, 71]. The scoping review identified inherent tensions between top-down and bottom-up driven dimensions of integrated care reform. The evidence gathered by this scoping review suggests that addressing this dichotomy requires both whole system structures, which allow for local flexibilities [19, 65-68].

This study was scoping in nature, thus allowing a rapid capture of a broad range of information on integration between primary care and social services in older adults with multimorbidity. It did not aim to answer a strictly defined research question and as a result, broad inclusion criteria were adopted, which allowed for the inclusion of a wide-range of study designs and grey literature to permit a higher-level overview of this research area and the related clinical provision. As much of social care delivery takes place outside of the NHS, and as a consequence of the relative paucity of research in this field, this approach was necessary to capture the diverse range of existing work in the field. There were high levels of heterogeneity amongst the study designs and settings which is a strength of this work but also challenging to collate and summarise comprehensively. The quality of the evidence presented was not assessed and those articles not written in English were excluded. As the study was focused on England, it is unlikely that non-English language articles would have substantially altered the results.

This scoping review is one of the first to examine the literature on integration between primary care and social services, with a particular focus on England. The findings are consistent with previous evidence outside of a primary care context, which highlights the need for greater consideration of wider health determinants in managing the increasingly diverse needs of older adults with multimorbidity [72, 73]. Earlier reviews on integrated care have also emphasised the need for more multidisciplinary and multi-sector co-operation within a single over-arching system [74]. The study highlighted that this system must incorporate traditional health and social care services, alongside voluntary, private and government organisations. Furthermore, the scoping review emphasised the value of time in allowing integrated care to embed. Although some previous reviews and policy calls argue that a more rapid and urgent pace is needed for integration due to rising demand, this scoping review suggests that a slower process of change is perhaps necessary to permit successful and long-lasting implementation at the local level [7]. This has been highlighted by a previous scoping review although it was not specific to primary care or social services [50, 59, 63, 74].

Finally, the tensions identified between top-down and bottom-up integrated care reform $[56,65]$ and related calls for whole system structures of integration allowing for local flexibilities, has been articulated in government policy but not yet operationalised [55]. To support this, the next steps will need to go beyond a scoping review towards more robust service evaluation and trials of whole-system multi-sector and multi-level integration interventions that address both clinical and social need.

\section{Conclusions}

This scoping review aimed to summarise current evidence, clinical provision and progress towards integrated primary care and social services for older adults with multimorbidity in England. It found studies describing 
individual sectors, which mainly focused on process improvements, while there was limited evidence of improved outcomes or resource use, nor evidence of provision or progress towards multi-level and multi-sector integration across services for older adults with multimorbidity. Wider determinants of population health are important, suggesting that integration that goes beyond primary care and social services to encompass a truly whole system approach across sectors is likely to be necessary to effectively address the needs of older adults with multimorbidity. This may take time to establish and will require local input. Further research evidence is required to support operationalising this approach and to examine the feasibility of implementing such a system within existing structures.

\section{Supplementary Information}

The online version contains supplementary material available at https://doi. org/10.1186/s12877-021-02618-8.

\section{Additional file 1.}

\section{Acknowledgements}

None.

\section{Authors' contributions}

HDM conceived the study idea, developed the study design, wrote the analysis plan, conducted the analysis, drafted and revised the article. GS contributed to the drafting and revision of the article, data extraction, and analysis. LH contributed to the screening of studies. MS contributed to the design of the study, advised on data analysis and revised the article. PL, HE and PR revised the article. HDM is guarantor. The author(s) read and approved the final manuscript.

\section{Author's information}

None.

\section{Funding}

The Primary Care Research Centre at the University of Southampton is a member of the NIHR School for Primary Care Research and supported by NIHR Research funds. HDM is an NIHR Clinical Lecturer and received an NIHR SPCR grant for this work: SPCR2014-10043. The views expressed are those of the author(s) and not necessarily those of the NHS, the NIHR or the Department of Health and Social Care.

\section{Availability of data and materials}

Data used during the current study are available from the corresponding author on reasonable request.

\section{Declarations}

\section{Ethics approval and consent to participate}

Ethical approval was not required for this scoping review and therefore not applicable.

The lead author affirms that the manuscript is an honest, accurate, and transparent account of the study being reported; that no important aspects of the study have been omitted. The opinions, results, and conclusions reported in this article are those of the authors and are independent from the funding sources.

\section{Consent for publication}

Not applicable.

\section{Competing interests}

None to declare.

\section{Author details}

${ }^{1}$ Primary Care Research Centre, University of Southampton, Aldermoor Health Centre, Aldermoor Close, Southampton SO16 5ST, UK. ²Department of Population Health, University of Southampton, Southampton, UK.

Received: 5 January 2021 Accepted: 9 November 2021

Published online: 03 December 2021

\section{References}

1. Barnett K, Mercer SW, Norbury M, et al. Epidemiology of multimorbidity and implications for health care, research, and medical education: a cross-sectional study. Lancet. 2012;380:37-43. https://doi.org/10.1016/ S0140-6736(12)60240-2.

2. Cassell A, Edwards D, Harshfield A, et al. The epidemiology of multimorbidity in primary care: a retrospective cohort study. Br J Gen Pract. 2018;68:e245-51. https://doi.org/10.3399/bjgp18X695465.

3. Kingston A, Comas-Herrera A, Jagger C. Forecasting the care needs of the older population in England over the next 20 years: estimates from the population ageing and care simulation (PACSim) modelling study. Lancet Public Health. 2018;3:e447-55. https://doi.org/10.1016/S2468-2667(18) 30118-X

4. Leutz WN. Five laws for integrating medical and social services: lessons from the United States and the United Kingdom. Milbank Q. 1999;77(1):77-110. https://doi.org/10.1111/1468-0009.00125.

5. Erens B, Wistow G, Mays N, Manacorda T, Douglas N, Mounier-Jack S, et al. Can health and social care integration make long-term progress? Findings from key informant surveys of the integration pioneers in England. J Integr Care. 2019:28(1):14-26. https://doi.org/10.1108/jica-05-2019-0020.

6. Kelly L, Harlock J, Peters M, Fitzpatrick R, Crocker H. Measures for the integration of health and social care services for long-term health conditions: a systematic review of reviews. BMC Health Serv Res. 2020;20:358. https:// doi.org/10.1186/s12913-020-05206-5.

7. Baxter S, Johnson M, Chambers D, Sutton A, Goyder E, Booth A. The effects of integrated care: a systematic review of UK and international evidence. BMC Health Serv Res. 2018;18(1):350. https://doi.org/10.1186/ s12913-018-3161-3.

8. Hughes G, Shaw SE, Greenhalgh T. Rethinking integrated care: a systematic hermeneutic review of the literature on integrated care strategies and concepts. Milbank Q. 2020;2:446-92. https://doi.org/10.1111/14680009.12459.

9. Kozlowska O, Lumb A, Tan GD, Rea R. Barriers and facilitators to integrating primary and specialist healthcare in the United Kingdom: a narrative literature review. Fut Healthc J. 2018;5(1):64-80. https://doi.org/10.7861/ futurehosp.5-1-64.

10. Fraser MW, Lombardi BM, Fraher EP. Integrated primary care and social work: a systematic review. Published Online First; 2018. https://doi.org/10. 1086/697567.

11. Tricco AC, Lillie E, Zarin W, et al. PRISMA extension for scoping reviews (PRISMA-SCR): checklist and explanation. Ann Intern Med. 2018;169:46773. https://doi.org/10.7326/M18-0850.

12. Valentijn PP, Schepman SM, Opheij W, et al. Understanding integrated care: a comprehensive conceptual framework based on the integrative functions of primary care. Int J Integr Care. 2013;13. https://doi.org/10. 5334/ijic.886

13. Fares J, Chung KSK, Passey M, et al. Exploring the psychometric properties of the rainbow model of integrated care measurement tool for care providers in Australia. BMJ Open. 2019;9. https://doi.org/10.1136/bmjop en-2018-027920.

14. Doessing A, Burau V. Care coordination of multimorbidity: a scoping study. J Comorbidity. 2015;5. https://doi.org/10.15256/joc.2015.5.39.

15. Colquhoun $\mathrm{HL}$, Levac $\mathrm{D}, \mathrm{O}$ 'Brien KK, et al. Scoping reviews: time for clarity in definition, methods, and reporting. J Clin Epidemiol. 2014;67. https:// doi.org/10.1016/j.jclinepi.2014.03.013.

16. BMJ (OPEN ACCESS), Page MJ, JE MK, Bossuyt PM, Boutron I, Hoffmann TC, et al. The PRISMA 2020 statement: an updated guideline for reporting systematic reviews. BMJ. 2021;372:n71. https://doi.org/10.1136/bmj.n71. 
17. Coulter A, Roberts S, Dixon A. Delivering better services for people with long-term conditions: building the house of care. 2013 http://www.kings fund.org.uk/publications/delivering-better-services-people-long-termconditions (Accessed 25 Nov 2020).

18. Clarkson P, Brand C, Hughes J, Challis D. Integrating assessments of older people: examining evidence and impact from a randomised controlled trial. Age Ageing. 2011;40(3):388-91. https://doi.org/10.1093/ageing/ afr015.

19. Petch A. Delivering integrated care and support: Institute for Research and Innovation in Social Services; 2014. https://www.iriss.org.uk/resou rces/insights/delivering-integrated-care-and-support-insight (Accessed 23 Nov 2020)

20. Poxton R. Joint approaches for a better old age: developing services through joint commissioning. London: King's Fund; 1996.

21. Dale H, Lee A. Behavioural health consultants in integrated primary care teams: a model for future care. BMC Fam Pract. 2016;17:97. https://doi. org/10.1186/s12875-016-0485-0.

22. Kadam U. Redesigning the general practice consultation to improve care for patients with multimorbidity. BMJ. 2012;345:e6202. https://doi.org/10. 1136/bmj.e6202 PMID: 22988307.

23. Jolly K, Bradley F, Sharp S, Smith H, Thompson S, Kinmonth AL, et al. Randomised controlled trial of follow up care in general practice of patients with myocardial infarction and angina: final results of the Southampton heart integrated care project (SHIP). The SHIP collaborative group. BMJ. 1999;318(7185):706-11. https://doi.org/10.1136/bmj.318.7185.706 PMID: 10074017; PMCID: PMC27782.

24. Ruiz M, Bottle A, Long S, Aylin P. Multi-morbidity in hospitalised older patients: who are the complex elderly? PLoS One. 2015;10(12):e0145372. https://doi.org/10.1371/journal.pone.0145372.

25. Watson J, Salisbury C, Jani A, Gray M, McKinstry B, Rosen R. Better value primary care is needed now more than ever. BMJ. 2017. https://doi.org/ 10.1136/bmj.j4944.

26. Sharp D, Lorenc A, Feder G, Little P, Hollinghurst S, Mercer S, et al. Trying to put a square peg into a round hole': a qualitative study of healthcare professionals' views of integrating complementary medicine into primary care for musculoskeletal and mental health comorbidity. BMC Complement Altern Med. 2018;18(1):290. https://doi.org/10.1186/ s12906-018-2349-8.

27. Butterworth JE, Hays R, McDonagh ST, Richards SH, Bower P, Campbell J. Interventions for involving older patients with multi-morbidity in decision-making during primary care consultations. Cochrane Database Syst Rev. 2019;2019(10):CD013124

28. Institute of Public Care - Oxford Brookes University. Evidence review integrated health and social care. https://ipc.brookes.ac.uk/publications/ publication_809.html (Accessed 24 Nov 2020).

29. Collins B. New care models: emerging innovations in governance and Organisational form. London: The King's Fund; 2016. https://www.kings fund.org.uk/publications/new-care-models. (Accessed 22 Nov 2020)

30. Curry N, Harris M, Gunn L, Pappas Y, Blunt I, Soljak M. Integrated care pilot in north West London: a mixed methods evaluation. Int J Integr Care. 2013;13(3). https://doi.org/10.5334/ijic.1149.

31. Lewis R. The organisation of care for people with multimorbidity in general practice: an exploratory case study of service delivery: University of Manchester; 2015. https://www.research.manchester.ac.uk/portal/files/ 54563666/FULL_TEXT.PDF. (Accessed 20 Nov 2020)

32. Bull D, Bagwell S, Weston A, Joy I. Untapped potential: bringing the voluntary sector's strengths to health and care transformation. 2016 Available at: https://www.bl.uk/collection-items/untapped-potentialbringing-the-voluntary-sectors-strengths-to-health-and-care-transforma tion\#.

33. Knowles SE, Chew-Graham C, Adeyemi I, Coupe N, Coventry PA. Managing depression in people with multimorbidity: a qualitative evaluation of an integrated collaborative care model. BMC Fam Pract. 2015;16:32. https://doi.org/10.1186/s12875-015-0246-5.

34. RAND Europe, Ernst \& Young LLP. National evaluation of the Department of Health's integrated care pilots. London: RAND Europe; 2012. https:// assets.publishing.service.gov.uk/government/uploads/system/uploads/ attachment_data/file/215103/dh_133127.pdf (Accessed 26 Nov 2020)

35. Briggs AM, Valentijn PP, Thiyagarajan JA, de Carvalho IA. Elements of integrated care approaches for older people: a review of reviews. BMJ Open. 2018;8(4):1-13. [021194]. https://doi.org/10.1136/bmjopen-2017-021194.
36. Salisbury C, Man M-S, Bower P, Guthrie B, Chaplin K, Gaunt D, et al. Management of multimorbidity using a patient-centred care model: a pragmatic cluster-randomised trial of the 3D approach. Lancet. 2018;392(10141):41-50. https://doi.org/10.1016/S0140-6736(18)31308-4.

37. Wistow G. Integration and the NHS reforms. J Integr Care. 2011;19(4):5-13 http://eprints.Ise.ac.uk/40083/ (Accessed 26 Nov 2020).

38. Stokes, J. (2016) Multimorbidity and integrated care. Thesis, The University of Manchester. https://www.research.manchester.ac.uk/portal/files/54589 975/FULL_TEXT.PDF (Accessed on 24 Nov 2020).

39. Aiden H. Multimorbidity: understanding the challenge: Richmond Group of Charities; 2018. https://richmondgroupofcharities.org.uk/sites/default/ files/multimorbidity_-_understanding_the_challenge.pdf. (Accessed 29 Nov 2020)

40. Daveson BA, Harding R, Shipman C, Mason BL, Epiphaniou E, Higginson IJ, et al. The real-world problem of care coordination: a longitudinal qualitative study with patients living with advanced progressive illness and their unpaid caregivers. PLoS One. 2014;9(5):e95523. https://doi.org/10.1371/ journal.pone.0095523.

41. Langford K, Baeck P, Hampson M. Networks that work: partnerships for integrated care and services. London: Nesta; 2013. Available at: https:// media.nesta.org.uk/documents/networks_that_work.pdf

42. Wistow, G., Gaskins, M., Holder H. \& Smith, J. Putting integrated care into practice: the north West London experience. Research report. 2015. https://akademia.nfz.gov.pl/wp-content/uploads/2016/06/nwl_resea rch_report_011015_final_methods_amends.pdf (Accessed 26 Nov 2020).

43. Cook G, McNall A, Thompson J, Hodgson P, Shaw L, Cowie D. Integrated working for enhanced health Care in English Nursing Homes. J Nurs Scholarsh. 2017;49(1):15-23.

44. Redding, D. (2018) Integrated care. In: C3 Collaborating for Health, Care and Support Alliance, Carers Trust, Carers UK, Centre for Mental Health, Healthwatch England, National Voices, The Patients Association, The Point of Care Foundation, Race Equality Foundation, VCSE Review and Volunteering Matters. The long term NHS plan and beyond: views from leaders in charities and voice organisations. Available at: https://richm ondgroupofcharities.org.uk/sites/default/files/priorities_for_the_plan.pdf

45. Wistow, G. Hope over experience: still trying to bridge the divide in health and social care. Published Online First: 1 August 2017.https:// www.ippr.org/ (Accessed 24 Nov 2020).

46. Banerjee S. Multimorbidity--older adults need health care that can count past one. Lancet (London, England). 2015;385(9968):587-9. https://doi. org/10.1016/S0140-6736(14)61596-8.

47. Sadler E, Potterton V, Anderson R, Khadjesari Z, Sheehan K, Butt F, et al. Service user, carer and provider perspectives on integrated care for older people with frailty, and factors perceived to facilitate and hinder implementation: a systematic review and narrative synthesis. PLoS One. 2019;14(5). https://doi.org/10.1371/journal.pone.0216488.

48. Care Quality Commission. Beyond barriers: how older people move between health and care in England. London: CQC; 2018. Available at: https://www.cqc.org.uk/sites/default/files/20180702_beyond_barriers. pdf

49. Vos J, Gerling K, Linehan C, Siriwardena AN, Windle K. Understanding care navigation by older adults with multimorbidity: mixed-methods study using social network and framework analyses. JMIR Aging. 2018;1 (2):e11054. https://doi.org/10.2196/11054

50. Goodwin N, Sonola L, Thiel V, Kodner D. Co-ordinated care for people with complex chronic conditions: key lessons and markers for success; 2013. p. 27. https://www.kingsfund.org.uk/sites/default/files/field/field publication_file/co-ordinated-care-for-people-with-complex-chronicconditions-kingsfund-oct13.pdf. (Accessed 20 Nov 2020)

51. Kodner DL, Spreeuwenberg C. Integrated care: meaning, logic, applications, and implications - a discussion paper. Int J Integr Care. 2002;2(4):None. https://doi.org/10.5334/ijic.67.

52. Timmins N. Leading for integrated care'if you think competition is hard, you should try collaboration. London: King's Fund; 2019. https://www. kingsfund.org.uk/publications/leading-integrated-care (Accessed 25 Nov 2020)

53. Ham C, Heenan D, Longley M, Steel DR. Integrated care in Northern Ireland, Scotland and Wales lessons for England: The King's Fund; 2013. https://www.kingsfund.org.uk/publications/leading-integrated-care. (Accessed 20 Nov 2020) 
54. Reeve J. Primary care redesign for person-centred care: delivering an international generalist revolution. Aust J Prim Health. 2018:10.1071/ PY18019. Advance online publication. https://doi.org/10.1071/PY18019.

55. Charles A, Wenzel L, Kershaw M, Ham C, Walsh N. A year of integrated care systems: reviewing the journey so far. London: The King's Fund; 2018. Available at: www.kingsfund.org.uk/publications/year-integrated-caresystems (Accessed on 2 Feb 2019)

56. Baylis, A. \& Perks-Baker, S. (2017) Enhanced health in care homes: learning from experiences so far. Overview. https://www.kingsfund.org.uk/publi cations/enhanced-health-care-homes-experiences. (Accessed $30 \mathrm{Nov}$ 2020). No page number.

57. Maxwell S. Contextualising the coordination of care in NHS trusts: an organisational perspective: Durham University; 2007. http://etheses.dur. ac.uk/2563/. (Accessed 20 Nov 2020)

58. Glasby J, Miller R. Ten lessons for integrated care research and policy - a personal reflection: managing community care. J Integr Care. 2020;28(1):41-6. https://doi.org/10.1108/JCA-11-2019-0047.

59. Royal College of Nursing. Integrated health and social care in England: the story so far. London: RCN; 2014. Available at: https://www.rcn.org.uk/ about-us/our-influencing-work/policy-briefings/POL-0814

60. Mcclellan M, Udayakumar K, Thoumi A, Gonzalez-Smith J, Kadakia K. Advancing integrated Care in England: a practical path for care transformation: Margolis Centre for Health Policy; 2018. p. 2018.

61. Zonneveld N, Raab J, Minkman MMN. Towards a values framework for integrated health services: an international Delphi study. BMC Health Serv Res. 2020;20:224. https://doi.org/10.1186/s12913-020-5008-y.

62. Holder H. Managing the hospital and social care interface: interventions targeting older adults: Nuffield Trust; 2018. https://www.nuffieldtrust.org. uk/research/managing-the-hospital-and-social-care-interface. (Accessed 27 Nov 2020)

63. Glasby, J., Miller, R. \& Posaner, R. (2013) New conversations between old players? The relationship between general practice and social care in an era of clinical commissioning. https://www.sscr.nihr.ac.uk/wp-content/ uploads/SSCR-scoping-review_SR006.pdf. (Accessed 20 Nov 2020).

64. Shortell SM, Addicott R, Walsh N, Ham C. The NHS five year forward view: lessons from the United States in developing new care models. BMJ (Clinical research ed). 2015;350:h2005. https://doi.org/10.1136/bmj.h2005 Clinical integration.

65. Humphries R. Integrated health and social care in England. Progress and prospects. Health Policy (Amsterdam, Netherlands). 2015;119(7):856-9. https://doi.org/10.1016/j.healthpol.2015.04.010.

66. Stirling S, Malcolm A, Corbett-Nolan A. Rethinking the integration agenda. Sedlescombe: The Good Governance Institute; 2013. Available at: https://www.good-governance.org.uk/services/rethinking-the-integ ration-agenda/

67. Public Health England. Health and care integration making the case from a public health perspective. London: PHE; 2013. Available at: https:// www.gov.uk/government/publications/health-and-care-integrationmaking-the-case-from-a-public-health-perspective

68. Oliver D. Guest editorial: integrated services for older people - the key to unlock our health and care services and improve the quality of care? J Res Nurs. 2015;20(1):5-11. https://doi.org/10.1177/1744987114568053.

69. Ham C. Integrated care. What is it? Does it work? What does it mean for the NHS? London: King's Fund; 2011. http://www.kingsfund.org.uk/sites/ files/kf/field/field_publication_file/integrated-care-summary-chris-hamsep11.pdf (Accessed 26 Nov 2020)

70. Grooten L, Vrijhoef HDM, Calciolari S, Guadalupe González Ortiz L, Janečková M, Minkman MMN, et al. Assessing the maturity of the healthcare system for integrated care: testing measurement properties of the SCIROCCO tool. BMC Med Res Methodol. 2020;19:63. https://doi.org/10. 1186/s12874-019-0704-1.

71. NHS England, Designing integrated care systems (ICSS) in England. An overview on the arrangements needed to build strong health and care systems across the country. London: NHS England; 2019. https://www. england.nhs.uk/wp-content/uploads/2019/06/designing-integratedcare-systems-in-england.pdf (Accessed 29 Apr 2021)

72. Singer $L$, Green $M$, Rowe $F$, et al. Social determinants of multimorbidity and multiple functional limitations among the ageing population of England, 2002-2015. SSM - Popul Health. 2019;8:100413. https://doi.org/ 10.1016/j.ssmph.2019.100413.
73. Pearson-Stuttard J, Ezzati M, Gregg EW. Multimorbidity - a defining challenge for health systems. Lancet Public Health. 2019;4:e599-600. https:// doi.org/10.1016/S2468-2667(19)30222-1.

74. Threapleton DE, Chung RY, Wong SYS, et al. Integrated care for older populations and its implementation facilitators and barriers: a rapid scoping review. International J Qual Health Care. 2017;29:327-34. https://doi. org/10.1093/intqhc/mzx041.

\section{Publisher's Note}

Springer Nature remains neutral with regard to jurisdictional claims in published maps and institutional affiliations.

Ready to submit your research? Choose BMC and benefit from

- fast, convenient online submission

- thorough peer review by experienced researchers in your field

- rapid publication on acceptance

- support for research data, including large and complex data types

- gold Open Access which fosters wider collaboration and increased citations

- maximum visibility for your research: over $100 \mathrm{M}$ website views per year

At BMC, research is always in progress.

Learn more biomedcentral.com/submissions 